\title{
FESTIVIDADES ANDINAS Y RELIGIOSIDAD EN EL NORTE CHILENO
}

\section{ANDEAN FESTIVITIES AND RELIGIOSITY IN NORTHERN CHILE}

\author{
Vivian Gavilán Vega $a^{1}$ y Ana María Carrasco G. $^{2}$
}

\begin{abstract}
El propósito de este trabajo es exponer resultados de investigación acerca de las festividades religiosas más importantes que celebra la población que se adscribe étnicamente al pueblo aymara en el extremo norte de Chile, zona fronteriza con Bolivia y Perú. Se trata de un estudio descriptivo e interpretativo de las fiestas en el contexto de las representaciones del tiempo-espacio, con el objeto de aportar data empírica que contribuya a una mejor comprensión de la cultura e identidad aymara. Este material indica que si bien las formas de los rituales van cambiando y se producen procesos de resignificación, estos no han sido suficientemente estudiados. Asimismo se propone que las transformaciones en el sistema de creencias y las prácticas religiosas se relacionan con los procesos de modernización ocurridos durante el siglo XX, mismos que han afectado de manera más tardía a las comunidades aquí estudiadas. Las instituciones eclesiásticas han impulsado cambios también; es posible observar que a mayor presencia de las mismas, mayor es la continuidad con la cultura cristiana hegemónica, existiendo siempre un proceso de apropiación local.
\end{abstract}

Palabras claves: cultura y religiosidad, identidades étnicas, religiosidad aymara.

The purpose of this paper is to present the results of our research on important religious festivities celebrated by the population ethnically ascribed as Aymara in the far North of Chile, an area bordering Bolivia and Peru. This is a descriptive study aiming to interpret these celebrations in the context of the representation of time-space, in order to provide empirical data that contributes to a better understanding of Aymara culture and identity. This material indicates that although the forms of these rituals are changing and subject to shifting meanings, they have not been sufficiently studied. We propose that these changes in the systems of religious beliefs and practices relate to the processes of modernization occurring during the twentieth century, which affected the communities studied here in more recent times. Religious institutions have also prompted changes; it is possible to observe that their increasing presence has resulted in greater continuity with the dominant Christian culture, together with the always extant processes of local appropriation.

Key words: Culture and religiosity, ethnical identities, aymara religiosity.

Las festividades religiosas que celebran hoy mujeres y hombres adscritos étnicamente al pueblo aymara que residen en las regiones de AricaParinacota y Tarapacá (Figura 1) constituyen un importante centro de atención para comprender el desarrollo histórico que ha experimentado esta zona y su impacto en las transformaciones culturales. Su estudio permite observar los procesos de elaboración de identidades colectivas en contextos sociohistóricos adversos para una cultura subvalorada por siglos.

Cualquiera sea la adscripción eclesiástica de las personas y familias, su religiosidad es una fuente de representaciones y construcciones simbólicas del orden social y cósmico que muestran a actores sociales con una fuerte voluntad por distinguirse de la población no aymara. Los datos acopiados aquí exponen una persistente creencia en antepasados locales, a quienes denominan como "indios" o "inka" (Gavilán 2005), que los hace herederos de una forma de vida diferente a la de las familias no indígenas, quienes la desconocen, subvaloran o descalifican. Esta percepción emerge de la discriminación negativa de la cultura aymara en la región. La relación intercultural ha estado marcada por el conflicto. Las comunidades han sobrellevado una lucha desigual. La iglesia católica y la protestante han sido actores centrales del proceso de colonización a través de la evangelización. Al mismo tiempo, ser herederos del manejo ecológico, tecnológico y del territorio les otorga legitimidad en una zona históricamente cuestionada por los Estados nacionales y legitimidad para reivindicar derechos étnicos ante el Estado de Chile.

1 Centro de Investigaciones del Hombre en el Desierto (CIHDE), Iquique, Chile. viviangav@ yahoo.com

2 Departamento de Antropología, Universidad de Tarapacá, Arica, Chile. amcarrasco@uta.cl 


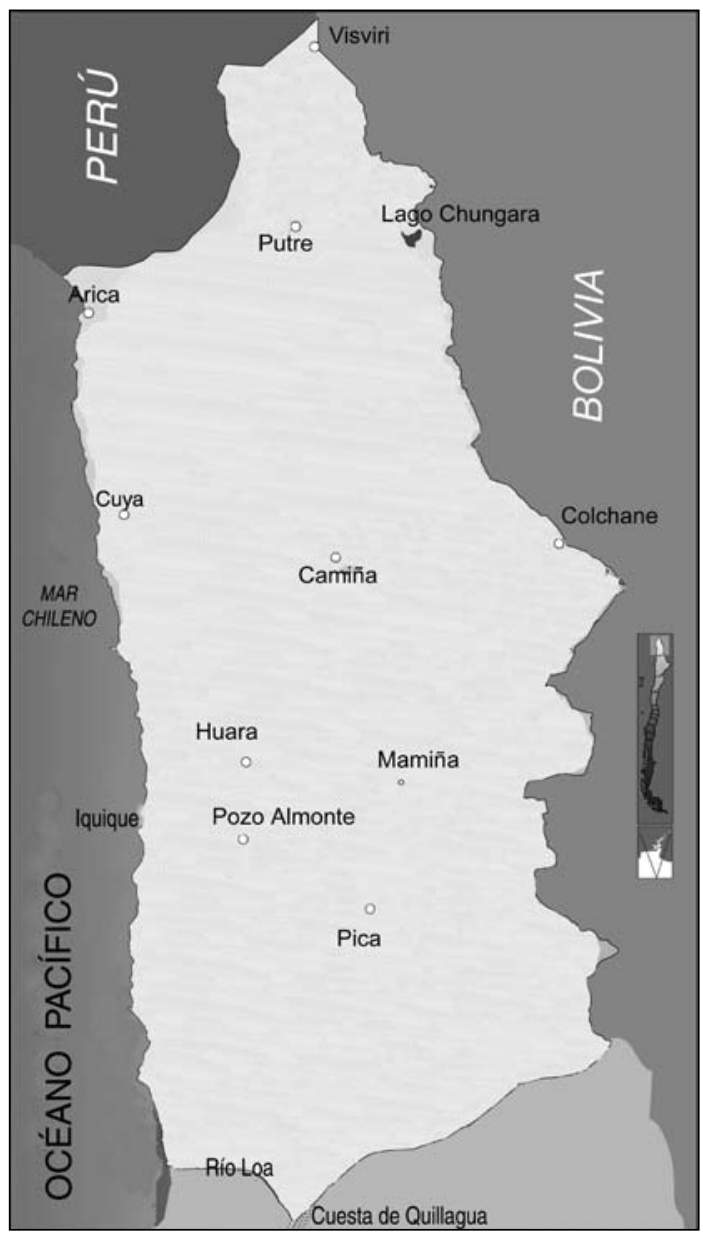

Figura 1. Mapa de la zona estudiada y localidades de las fiestas patronales más inclusivas.

Map of the studied zone and locations of the 'fiestas patronales' more inclusive.

Se exponen aquí antecedentes empíricos recogidos a través de un trabajo etnográfico y entrevistas realizadas durante la década de los noventa tanto en la zona rural como urbana. Los aportes de otros investigadores, principalmente de la región que hoy pertenece a Chile y en menor medida de Bolivia, forman parte de la reconstrucción que se realiza para ubicar la fiesta en el espacio-tiempo y para proponer interpretaciones.

Las referencias empíricas incluyen a la población de origen altiplánico o precordillerano. Únicamente con fines de análisis y exposición se separan las fiestas que marcan los pasajes de las fases del ciclo anual agrícola y ganadero de la celebración de las fiestas dirigidas a los santos/as patronos/as. Como se observará, ambas se superponen y siguen la misma estructura con variaciones parciales.

\section{La Religiosidad Aymara}

En general, existe consenso en que la religiosidad actual de la población de origen indígena es producto de las diversas expresiones religiosas nativas que imperaron durante el período prehispánico, especialmente aquellas dirigidas por el Estado Inca y la imposición del cristianismo por parte de la iglesia católica y la protestante. El debate existe en torno a cómo calificar estas prácticas que provienen de diversas tradiciones. Algunos señalan que existiría una síntesis entre las creencias antiguas y el cristianismo. Se habla de integración para referirse a cómo la tradición indígena incorporó el evangelio, contexto en el que la mitología andina sería el antiguo testamento de la religiosidad contemporánea, entendida como una variante del cristianismo ${ }^{1}$ (van Kessel 1992a). Si bien esto se concibe como sincretismo religioso, otros comprenden este concepto como una mezcla o yuxtaposición de las creencias indígenas y cristianas, puesto que existiría el dualismo: religión clandestina/religión oficial ${ }^{2}$.

Grebe (1996) sugiere que existiría un proceso de interacción de componentes indígenas e hispánicos, que produciría "tres orientaciones: (1) la coexistencia o yuxtaposición de componentes culturales que fluyen a través de vías paralelas independientes manteniendo su individualidad; (2) la transformación abierta y continua de sus componentes que se ajustan adaptativamente a los cambios del entorno sociocultural y físico, y (3) la fusión o integración bicultural (o multicultural) que promueve la generación de mestizajes y sincretismos" (Grebe 1996:86).

El tejido de tradiciones que explican la celebración de las festividades y las formas que adoptan puede llamarse sincretismo cultural, mestizaje, hibridismo o de otro modo, pero lo que subyace a éstos es una concepción del cambio cultural y del concepto de cultura. Quienes se orientan por una mirada dicotómica al oponer tradición cultural autóctona y no autóctona, moderno-no moderno, tienden a basarse en una idea esencialista de la cultura (Guerrero 1994; van Kessel 1980:200). Los estudios sociohistóricos acerca de la conformación de la sociedad y cultura latinoamericana confirmarían la afirmación realizada por Roger Bastide de que lo cultural no puede estudiarse 
independientemente de lo social. Ello implica un concepto dinámico de cultura, que la considere como proceso de construcción, desestructuración y reconstrucción del sistema de creencias y actividades (Bastide citado en Cuche 2004). De esta manera no existirían de un lado culturas puras y, del otro, culturas mestizas. Tanto aymaras como no aymaras compartimos un espacio social y cultural común: capitalista y cristiano. Los procesos de modernización impulsados por el Estado-nación, no obstante, han afectado de manera diferenciada a las colectividades. En los valles se produjeron grandes transformaciones tanto en tiempos coloniales como republicanos. Durante el período colonial los sistemas sociales y económicos funcionaron con un mayor control de parte de las elites dominantes, entre las que se encontraba la iglesia y sus programas de evangelización. En consecuencia, se puede suponer que en las zonas más alejadas de estos centros de poder la tarea de evangelización no fue tarea fácil y por lo tanto los cultos locales no pudieron ser reprimidos. Con la república, se vieron afectados por los modelos de desarrollo regional (explotación del guano, nitrato y Puerto Libre o Zona Franca). El Equipo Pastoral Andino de la Iglesia Católica de Iquique sugiere que las comunidades rurales fueron progresivamente abandonadas a partir de la década de 1920, debido a la concentración de sus agentes pastorales en los pueblos salitreros y en la costa (van Kessel 1990 citado en Guerrero 1990).

Una de las consecuencias visibles de estas dinámicas son los movimientos de población en toda la región, los cuales siguen siendo muy importantes. De esta manera, la comunidad que se adscribe al pueblo aymara es heterogénea, social y culturalmente. Se observan diferencias entre la zona altiplánica, los valles y entre los residentes urbanos, por comunidad, por familias y por personas. Asimismo, hay variaciones entre el altiplano norte y sur de Tarapacá. En el altiplano de la provincia de Parinacota se percibe la desaparición paulatina de muchas prácticas rituales que hasta hace tres décadas se realizaban. Mientras que en el altiplano de la provincia de Iquique continúan, no obstante la tendencia a su reemplazo. Sin embargo, la diferencia es mayor si comparamos la zona de valle con la altiplánica. $\mathrm{Al}$ interior de cada una de las zonas geográficas mencionadas las prácticas varían de acuerdo a la adscripción a una u otra iglesia, a la posición generacional de los sujetos y a la pertenencia a organizaciones que promueven derechos culturales.

Las iglesias a las cuales dicen pertenecer la mayoría de los aymara son: Católica, Evangélica Pentecostal, Evangélica Nazarena; Adventista, Sabática del Séptimo día, Evangelio Cuadrangular, Metodistas Pentecostales, Testigos de Jehová. Con excepción de la primera, todas son de reciente data. Quienes profesan el culto protestante tienden a dejar de practicar, de manera abrupta o paulatina, ceremonias y rituales que realizaban siendo católicos. Pero esta tendencia no es patrimonio exclusivo de la adopción de una nueva religión, sino se relacionaría con los procesos de escolarización y de una nueva inserción en los mercados de trabajo. Quienes se adscriben al catolicismo mantienen la vieja tradición de festividades del ciclo anual y vital, a las que clasifican como "costumbres". Sin embargo, poco sabemos del fenómeno de la conversión, tanto del "catolicismo" al "protestantismo" como de éste a la recuperación de las "costumbres"3.

Observamos que las viejas generaciones saben y realizan los rituales que se incluyen en "la costumbre" con mayor propiedad que las nuevas. Así, hallamos que a mayor edad, mayor escolaridad, residencia principal rural y adscripción católica mayor vinculación con las "costumbres". Proposición que habría que matizar en el caso de la población urbana, puesto que las organizaciones que reivindican derechos étnicos enfatizan en la especificidad cultural como un elemento central para diferenciarse del resto de la población regional.

A pesar de estas distinciones, existe un sustrato ideológico común que configura un modelo teórico que orienta a la acción. Pero la continuidad religiosa afirmada por los aymara de hoy se relaciona más con el deseo de diferenciación cultural, es decir, con la identidad contrastada. Las descripciones de las fiestas y la recuperación de la memoria colectiva que se hace en este artículo para acceder a significados buscan comprender esta diferencia.

\section{La "Costumbre"- Las Festividades en el Calendario Anual}

Los datos etnográficos acopiados permiten sostener que las festividades se entienden mejor en el contexto de la concepción del tiempo-espacio. La celebración de las ceremonias y rituales más importantes enfatizan en los cambios climáticos, eclipsando el calendario solar. Se distinguen tres 
momentos en el ciclo anual, directamente asociado al trabajo agrícola y ganadero. Las fiestas marcan el tránsito de una temporada a otra a través del culto a sus deidades y antepasados y se orientan a celebrar la fertilidad como deseo de bienestar y abundancia, a la muerte-vida en un permanente ciclo del devenir.

Tal como ha señalado van den Berg (1989), el calendario anual se concibe de un modo circular, siguiendo el principio de la bipartición y la tripartición (van den Berg 1989), y van Kessel para Tarapacá (van Kessel 1992b, 1996, 2007). La bipartición sigue el orden de los solsticios de invierno y verano. El segundo, se basa en el ciclo climático que distingue tres estaciones: una época seca y tibia, una lluviosa y cálida y una fría y seca.

El Sol, Inti o Dios, pensado en términos antropomorfos, se desplaza por un universo que contiene la vida (Pachamama). Este movimiento se representa como ciclo vital: Nacimiento, Desarrollo, Muerte, Renacimiento. Estos términos de las fases del ciclo vital de las personas son: wuawa (bebé dependiente)-yocalla (niño)-imilla (niña)-wayna (joven hombre)-tawajo (joven mujer)-chacha-warmi (matrimonio) achichi-apache (abuelo-abuela) jiwata ("muerte").

La representación del transcurso del tiempo en el espacio se entiende siguiendo la interpretación de un día: en el alba el sol se levanta desde el este, asciende sobre las laderas inferiores durante la mañana, descansa encima de las laderas centrales en el mediodía y sube a la cima de la montaña donde muere en el oeste. Durante el crepúsculo el lago o el mar se traga al sol, este se hunde hasta el fondo del lago y desciende nadando por los manantiales, de donde emerge el sol joven. Se utilizan analogías de la vida humana y de las plantas para explicar el diario nacimiento y muerte del sol (Bastien 1996).

Con el solsticio de invierno el sol se distancia hacia su punto más lejano, el sol está muriendo para volver a nacer. Ha comenzado el nuevo ciclo, lo que en el mito aparece como el retorno del sol (Wilka Kuti). Los habitantes del altiplano viven este momento en recogimiento. Algunos comuneros de Putre recuerdan que hasta los años sesenta se tocaban tambores para pedir al sol su regreso. Recuerdan que a fines de la década de 1980 e inicios de la década de 1990 algunas personas con residencia principal en Arica promocionaron el Inti Raymi -fiesta que se celebra en Cusco cada año- como una estrategia para recuperar tradiciones olvidadas y reafirmar la identidad indígena. En lengua aymara Machac Mara o año nuevo. En las comunidades de Isluga y Cariquima no se registran fiestas públicas. Algunas familias propician el ganado, principalmente de ovinos. En Isluga existe cierto temor por las bajas temperaturas que imperan a fines del mes de junio, especialmente el día de San Juan. Por ello, cuando comienza su nuevo ciclo se observa mayor tranquilidad entre los habitantes.

A fines de julio e inicios de agosto se transita de una época fría y seca a otra tibia y húmeda. Es año nuevo y el comienzo de las actividades agrícolas. Pachamama o Santa Tierra "tiene hambre, sed, está abierta" para recibir las ofrendas rituales. Se trata de dar fuerza a Pachamama para fortalecer su producción y propiciar sus bondades: alimentos, metales, dinero.

Se inicia el período de siembra, la que es pensada como el inicio de la vida humana. Es como embarazo. La memoria colectiva en Isluga y Cariquima recuerda que la festividad de la siembra consiste principalmente en ofrecer una wilancha, es decir, el sacrificio de una llama en un ritual en el que la sangre y el corazón del animal son el alimento y el cariño principal tanto para Inti-Dios, representado en la primera luz del día, como para Pachamama, representada en la tierra, la pirka o piedra, la vertiente, el cerro. Esta ceremonia forma parte de una mesa: banquete para las divinidades y para oferentes y acompañantes. Hay cantos para cada producto, para la quinua, para la papa, que llaman Bendición de quinua o de papa. Así Pachamama está contenta y se siente bien.

El ofrecimiento de la sangre implica dar más vitalidad o "ánimo" a Pachamama para que germine con fuerza. La sangre es indispensable para contribuir a la buena tierra, pero la semilla asociada a Jesús es parte necesaria para la fecundación. Algunas comunidades de Isluga celebraban Pukar Mallku Pukar T'alla ${ }^{4}$, representaciones de una pareja de abuelos (achachilas) protectores del pueblo. Sobre piedras en una loma se disponían talegas con productos agrícolas y se vestían a la usanza antigua. Cada año la comunidad propiciaba esta fiesta en su honor que estaba a cargo de un alférez o patrón. Se ofrece una mesa con bebidas (chuwa), incienso (kopal), hoja de coca, dulces, productos asociados a la fertilidad. En ésta como en todas las fiestas propiciatorias, comienza con la ceremonia de la antevíspera en la que se recuerda a los antepasados. Esta ocurre con luna nueva o llena para invitarlos al 
festejo con chicha y licores para terminar cuando "raya el sol" con el sacrificio o wilancha. Sigue la fiesta durante tres días en torno al cerro y la plaza del pueblo.

En la década de 1990 el año nuevo fue extensamente celebrado por las organizaciones de jóvenes aymara en Arica. Todo el mes de agosto era propicio. A través de la contratación de un yatiri (sabio), las familias ofrecían una wilancha y mesa en cerros aledaños, donde se comparte y festeja en honor a Pachamama. La ceremonia se iniciaba a la medianoche, momento en que se pide por un buen año. Sobre la mesa ofrecida se instalan las peticiones de los invitados: dinero, casa, camiones; y "los proyectos", hojas escritas que se disponían en la mesa ritual para auspiciar trabajo y dinero. A la amanecida luego del sacrificio se entierran el corazón y las entrañas, para luego compartir un asado en el mismo lugar.

En este período, en la zona altiplánica la limpieza de canales, regadíos y siembra convoca a Pachamama.

A fines de octubre, inicio del período de lluvias, se celebra un segundo ritual de pasaje. Es el día de los muertos y el regreso de los ancestros. Se transita hacia el período húmedo y tibio. Se cree que el sol avanza en su desarrollo; representa la juventud (wayna-tawaju). Es la etapa propicia para la diversión y sensualidad. Se trata de una época peligrosa: los ancestros (o condenados) visitan a los comuneros. Se debe compartir con los Achachilas y también con los finados recientes. Aquellos que han muerto durante los últimos tres años serán festejados.

En Guallatire, en el sector altiplánico de la comuna de Putre, recuerdan cómo en los años setenta se elegía alférez y mayordomo para celebrar la Fiesta de Todos los Santos:

Cada familia a la que se le había muerto un pariente en los últimos tres años preparaba una especie de estante con un declive en su casa (tumba) ${ }^{5}$. En ese lugar se colocaban panes especialmente preparados y la comida preferida del finado, se agrega alcohol, vino y otros alimentos, flores y velas. $\mathrm{Al}$ lado se coloca otra mesa con comida para los invitados que van a llegar de noche. Cuando llegan se reza, se come algo y se bebe. Todas las familias visitan estas casas al atardecer de una en una para amanecerse, comiendo y bebiendo según el orden del mayordomo. Durante la noche un grupo de niños a cargo de un adulto tocan las campanas de la iglesia. Se iba al cementerio donde hacían una fogata y juegan a la pelota, al naipe, etc. Ahí se amanecen y algunos se embriagan. Al otro día de mañana se llevan flores al cementerio. A mediodía se hacía de nuevo el circuito de la noche anterior pero ahora van recogiendo la comida que se puso en el estante junto a un "cantor" (rezador) para los finados, en latín. Se desarman luego los estantes y la casa queda igual que antes. Terminado esto, todos van al cementerio acompañados con una banda que entona una marcha fúnebre. Vuelven a las casas.

El día dos el mayordomo se levanta temprano y prepara una especie de carnaval. Dos jóvenes se disfrazan de mujer (carnavales) y van visitando las casas. Esto dura toda la tarde. Al finalizar la tarde comienza el despacho en el cerro para enterrar todos los santos y desenterrar el carnaval, comienza la época de carnaval; actividad realizada por un grupo de cuatro o cinco personas. Enterraban un "mono", un muñeco que representaba a todos los santos. Concluido el entierro-desentierro, volvían cantando y tocando música de carnaval. Se encontraban con otro grupo de jóvenes en el pueblo preparados con instrumentos de vientos para acompañar los cantos y melodías propias de esta época. Allí esperan todos los habitantes en parejas para bailar por las calles durante una noche. De esta manera, quedaba oficialmente inaugurada la época de carnaval ${ }^{6}$.

Esta descripción ofrece un cuadro del culto a los muertos y la importancia que la población andina asigna a la memoria de los antepasados. Si bien en la actualidad no se practica de manera comunal, el tránsito de una temporada a otra se marca a través de la música. Poca gente se atreve a interpretar los cantos y melodías de carnavales en épocas que no corresponde por temor al poder de los ancestros.

En la precordillera de la actual provincia de Parinacota la siembra de papas se realiza a mediados de noviembre. La fiesta, nominada como 
Pachallampe, consiste en horadar la chacra con la chonta, un pequeño chuzo aplanado que se empuja con el pie y luego se levanta para dejar espacio a la colocación de la semilla. Se ofrece una wilancha a Pachamama y una mesa en señal de cariño y reciprocidad y pedir a los seres tutelares una buena cosecha. La temporada cálida y húmeda representa un tiempo de peligros, los "condenados" o antepasados cohabitan el mismo espacio/tiempo.

El solsticio de verano parece no ser fuente de celebraciones colectivas. En Isluga y Camiña la fiesta patronal más importante es Santo Tomás, el 21 de diciembre ${ }^{7}$. En el altiplano, esta temporada es dedicada a Mallkus y T'allas, antepasados protectores del cerro, ojos de agua (Jutur Mallku-Jutur T'alla) o vertientes (Seren Mallku Seren T'alla) o pirkas para pedir por la multiplicación del ganado, por la salud, por la cosecha, por el bienestar. Se realiza la marcación o Quilpa y se "ama" a los animales en su período de apareamiento y nacimiento de nuevas crías; del mismo modo que se ha ofrecido cariño a las chacras de quinua y papas. La fiesta completa puede repetirse o efectuarse cada tres años. Aunque esta puede celebrarse en distintas fechas, la mayoría prefiere esta temporada y principalmente en el día "Compadre", dos semanas antes de carnaval para los Mallkus, y el día "Comadre" para las T'allas, una semana antes. A ellos se les pide en la fiesta del ganado o Wayño. En esta se agregan a la mesa ritual un gato silvestre llamado titi y un pato acuático, llamado chullumbi embalsamados, los que se piensan como cuidadores del ganado. Una noche de los tres días festivos se realizan representaciones teatrales en torno a fogatas. Se muestran aquí las actividades ganaderas. Las mujeres representan hembras de llamas y alpacas, los hombres a los machos, dirigidos por un awatiri o pastor que los va laceando para llevarlos a los patrones. Aquí se transa el valor del animal, se trata de negociar el precio buscando el máximo valor.

La fiesta de carnavales o "floreo de la gente" marca el pasaje a la temporada fría y seca, simbolizada con el sol maduro y asociada a lo masculino y a la madurez que se representa en el matrimonio. Es por definición el espacio de reproducción social de la comunidad. Son tres días de fiesta en la que aparece la organización espacial y social de la "Marka" o pueblo central, en torno a las mitades: Arajj Saya y Manqha Saya. En ella se pone en escena la adscripción y pertenencia a un grupo de parentesco y comunal identificado por antepasados. Los rituales se dirigen a los seres protectores de la comunidad actual, quienes vigilan el sistema normativo-ético y el orden en la naturaleza.

Se propicia la fertilidad humana, los intercambios sexuales entre mujeres y hombres. Las mujeres usan la expresión "dar cariño a la gente". La mayor parte de los actuales matrimonios se han conocido en ellas y se han iniciado sexualmente con sus maridos. Hombres y mujeres son los actores centrales. Como miembros de una unidad familiar tienen una ubicación estricta, por pueblo, por estancia y por comunidad. En la plaza central se forman ruedas de mujeres solteras por mitad o Saya para cantar y bailar. La rodean las comparsas de varones casados y solteros que cantan y bailan al son de las bandolas. Para esta fiesta, tanto las jóvenes como los jóvenes se preparan con bastante anticipación. El ideal para las primeras es tener aksos o Urkus (vestido femenino) y Wak'as (fajas) confeccionados por ellas y tejidos especialmente para la ocasión; Hawayus (mantas para cargar) y culebrillas (adornos) que han sido preparadas por el padre o hermano. Los accesorios como aretes, collares, trabas, cintas para el cabello y sombreros nuevos, también son indispensables para lucir bellas. Ellos se esmeran en mostrar pantalones (jeans) y camisas nuevas, también ostentando radios u otros artefactos que hablan de su éxito económico. En Cariquima, las comparsas que salen con el alférez desde su estancia, haciendo paradas en lugares tradicionalmente prefijados para incorporar a otros grupos de la misma mitad, llegan al pueblo en la tarde. Se inician las ceremonias en la iglesia y la torre para luego pasar al "Munaypata", nombre que recibe el lugar que cada una de las mitades dispone a la orilla del pueblo, en medio de la pampa. En el centro del lugar, se hacen los primeros rituales dirigidos por los pasantes de cada mitad. De allí parten las comparsas, las que se encuentran justo en la mitad de la calle que une a ambas parcialidades. En Isluga, en cambio, los alféreces se deben ir el sábado al Pueblo o Marka para iniciar la ceremonia de antevíspera, pues la entrada de la fiesta se hace al amanecer del día lunes.

Toda la fiesta consiste en competir y compartir entre las mitades. Arajj Saya es de mayor prestigio que Manqha Saya. La primera se representa como masculina y la segunda como femenina. La gente de la mitad de arriba se dice que son de la cordillera (parte alta); mientras que la de abajo son pampa o suripampa $^{8}$. Los cantos enuncian la identidad de los grupos sociales quienes compiten durante la fiesta. 
Estos son repetitivos, entonados e improvisados primero por un hombre adulto, acompañado de una bandola y luego contestan las mujeres en sus tonos agudos. Se trata de ser creativo y estimular el afecto, la risa y la sensualidad de los participantes. Bandolas y tarkas acompañan las danzas en el centro de la plaza; mientras que bandas de trompetas y saxofones lo hacen en la sede social. Los niños y demás personas que han quedado a cargo del ganado y no asisten a la fiesta del pueblo por lo general temen la visita de los condenados. Así como es tiempo de alegría, es también un tiempo lleno de peligros, donde confluyen el bien y el mal. En las comunidades del altiplano norte de la región se piensa que durante el carnaval suelen ocurrir sucesos extraños: "carnaval era juntarse todos, una alegría del año, un desahogo, antes que hubiera fiesta religiosa". Otro comunero sugiere que "es como jugar con la tentación del mal, todos estos disfraces es una representación de que existe el mal, entonces carnaval es como jugar con el mal".

En la zona sur, en cambio, la idea del mal está presente, mas no es tan marcada. Sin embargo, es persistente en las personas adscritas a la religión pentecostal. Bouysse-Cassagne y Harris (1987:39) señalan que el nombre aymara del carnaval, anata, quiere decir "tiempo de juego", pero también es conocido como supay phista, lo que quiere decir fiesta de los diablos.

La celebración es dirigida por los caciques (Mallku-T'alla por cada una de las mitades) y los Mayordomos (Mujer-Hombre, dos por cada mitad), quienes serán los encargados de agradecer a las deidades los favores concedidos y para pedir bienestar para su familia y su parcialidad. Los pasantes visten sus mejores atuendos y cargan las mejores especies vegetales cultivadas y los pastos del ganado. Quinua, habas, membrillo, flores, etc. La figura de las parejas son las mismas que las representadas en los cerros para recordar a los achachilas (abuelos) en medio de los cerros.

Las ceremonias rituales se dirigen a todos los seres tutelares que proveen alimentos y bienestar a los hogares: En Cariquima se ofrenda a Pachamama, Wanapa T'alla, la montaña mujer que rodea a la comunidad; cuyo nombre ritual es María Cruzani, a Vilacollo Mallku, etc. Durante los carnavales Torre Mallku y T'alla, entidades que se ubican en la torre de la iglesia y que protegen el pueblo, adquieren relevancia. Esta es adornada con cintas y las primicias agrícolas y pastos, del mismo modo que a las personas y se les rinde culto durante los tres días de fiesta. Una serie de signos que suceden en la fiesta anunciarán si el año será próspero o no. Uno de ellos es que el día del lanzamiento de los membrillos ambos caciques, mayordomos y gente de cada mitad ondean la Torre Mallku y T'alla; quien le da a las campanas gana e implica que será un buen año. En el campanario se encuentra la pareja mallku-t'alla. La campana hembra, como le dicen los comuneros, es tocada en el día de los "membrillazos".

En Isluga también se identifican estas divinidades. Grebe (1981) sugiere que Torre Mallku y Santa-Belin T'alla son los espíritus guardianes de la torre y de la iglesia y que mediatizan Uywir Parte con Dios Parte; vale decir, las dos partes de la religión aymara, la cristiana y la autóctona. Son concebidos como una pareja mixta antropomórfica y son recordados solamente en carnaval. Se le ofrecen wilanchas durante la fiesta fuera de la iglesia (Grebe 1981). Estas mismas entidades son descritas por G. Martínez (1989) como Santa Vitalina, Torre Mallku y Santa Plaza, tríada semejante a los santos patronos de Isluga: Concepción T'alla, Santo Tomás y Santa Bárbara. En esta comunidad, el día de los membrillazos se realiza entre los hombres de cada mitad, como una especie de lucha simbólica entre ambas. Cuando se ha terminado, cada cacique ondea la torre.

Esta etapa del año concluye con el entierro de los carnavales. Se inicia la siguiente temporada, seca y fría, como fase final del camino del sol, o sea, la fase final del ciclo vital. En Cariquima se celebraba la Pascua de Resurrección, momento en el que se reelegía a los nuevos caciques, como dirigentes rituales y políticos. En el altiplano comienza la cosecha de quinua y papas. En señal de agradecimiento se celebraba la fiesta de la cosecha:

En tiempo de cosecha los abuelos tenían su costumbre, hacían wilancha para sembrar, tiraban sangre. En una boda invitaban a la gente, hacían asado. Después, Likina que decían, que traían en carga de llamito, a la casa recogiendo su bendición, la cosecha, entonces lo esperaban al dueño de la producción entonces los obreros están descargando de los animales, amontonando más grande el costal sahiri que se llama y lo espera con copalita, y la arruman adentro de la casa. Pero, cosecha de 40, 50 quintales. Un costal 
hará de un saco, costal eran tejidos. Entonces, ahí lo ponen como una persona como una mujer le colocaban una manta rosada, una llijlla, su sombrerito, sus collares, sus topos. Ahí enseguida, ya se pide y se cantaba cada cosecha tenía su propia entonación en bandola y cantos, la quinua dicen juiran mama y papa charka mama, las habas. Los cantos dicen te vestiste pollera verde y ahora vendiste la pollera verde, así, dicen. Aquí se viste mujer no más no se viste hombre. Es que siempre mujer mantiene en el hogar, por eso viste de mujer, no de hombre. El hombre es de calle, quien es más dueña de la casa, la mujer. No es pareja aquí, cualquier producción de mujer es ${ }^{9}$.

En los meses de mayo-junio se prepara la papa chuñu (papa seca de guarda). Se simboliza así la etapa final de la vida (Achichi para los hombres, Apache para las mujeres). Viene pues la muerte del Sol (Jiwata ${ }^{10}$, para ambos géneros), para re-nacer e iniciar un nuevo ciclo vital (Figura 2).

\section{Santos, Santas y Vírgenes: Patrono/as del Pueblo}

Cada una de las estancias tiene o tenía por lo general una iglesia católica, con un o una santo/a o virgen que protegía a las familias. Cada comunidad étnica cuenta con un Patrono/a principal, asignando así una clara jerarquización que en la escala mayor ubica a aquellos de mayor inclusión poblacional. De mayor a menor importancia: Patronas/nos de la unidad familiar, de estancias, de comunidad o grupo étnico. Igual que mallkus y t'allas hay santos y vírgenes patronos de varios grupos étnicos. Este es el caso de la Virgen de Copacabana y San Santiago de Yungullo, ambos en territorio boliviano. Hasta la década de los setenta los caciques de Isluga y Cariquima viajaban a los pueblos del mismo nombre para pedir por su comunidad en agosto. La necesidad de este peregrinaje, que según dicen duraba varias semanas a pie, se revelaba a los caciques y estos debían cumplir. Un comunero de Cariquima nos relata que:

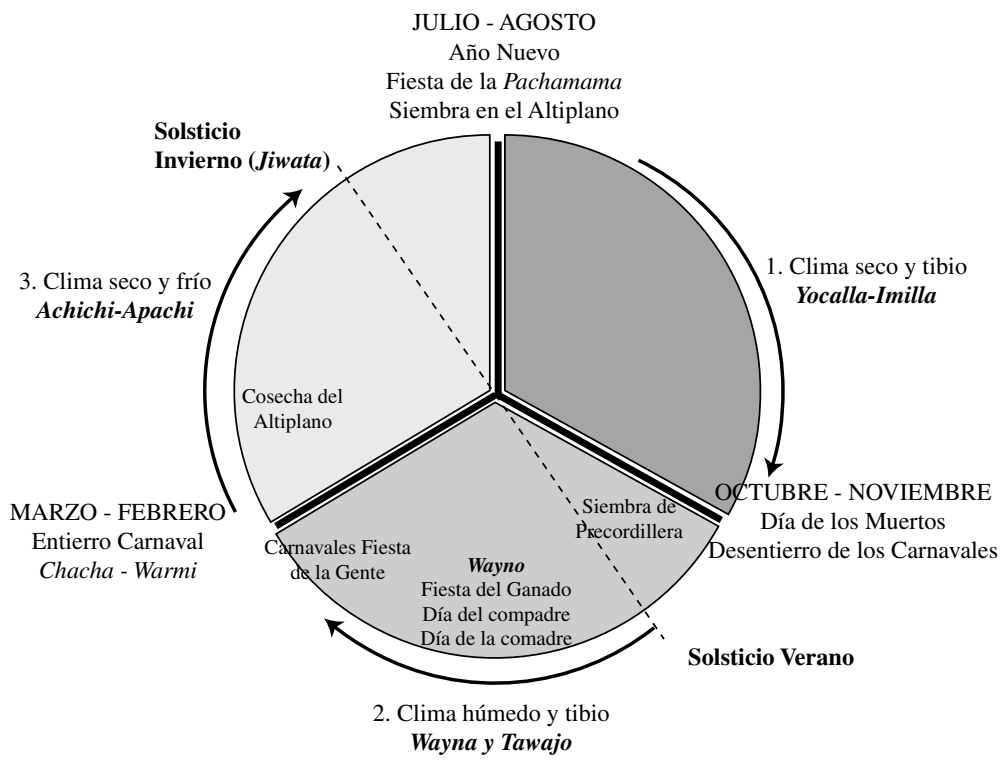

Figura 2. Reconstrucción gráfica del tiempo y fiestas asociadas a las transiciones climáticas.

Graphic depiction of the temporary work and festivities associated with transitions weather. 
antes del primero de Agosto, había que... En Yungullo había una iglesia mucho más antes fundada ya; entonces, mediante un yatiri $^{11}$, uno que indicaba por sueños, uno que indicaba por hojas de coca... decían que había que ir a Yunguyo, pero eso no era en forma obligatoria, sino que indicaban de que había que ir a Yunguyo a pedir la lluvia, a pedir la buena siembra; había que mandar misa al... a los patronos de Cariquima. Cuando había un acuerdo de ese tipo, iban los caciques para allá. Entonces decían que... -iban a pie no más-... llegaban allá y le decían: -Mire, Cariquima viene aquí a solicitarle para este año una buena lluvia-... allá habían patrono de Yunguyo, San Santiago- y si San Santiago le concediera lluvia para ese sector de Cariquima ${ }^{12}$.

Una mujer de Isluga agrega que:

Antes se usaba cacique, entonces ese que se hace responsable de comunidad de toda la fiesta, tienen fecha fijada para ir pa allá, pa Bolivia, pa Copacabana, pa pedir, a pie tiene que andar. La última vez hasta Yungullo no más llegaron, no llegaron hasta allá, pero es igual no más. Donde está Tata Español, Tata Caballero, este no más se pidieron. San Santiago, su jefe en Yungullo está. Un mes ida y vuelta. Tiene que ayunarse pa pedir, tiene que reunirse para sahumar incienso, kopal y para prender vela, cuatro mayordomos tiene que procurarse y los dos caciques, seis personas como jefes tiene que andarse ${ }^{13}$.

Las rogativas a estas dos importantes deidades se efectuaban en agosto; $y$ las peticiones son similares a las realizadas a Pukar Mallku-Pukar T'alla. Si bien San Santiago se celebra el 25 de julio y Candelaria de Copacabana el 2 de febrero, la peregrinación se realizaba a inicios del nuevo año.

El levantamiento realizado en la mayor parte de las localidades altiplánicas muestran a cuatro santos/as patronos/as de cada comunidad histórica $\mathrm{y}$ en pareja. Sus celebraciones siguen el calendario cristiano, aunque tienden a concentrarse en el perído agosto-diciembre.
En términos de representaciones, los santos y santas se asemejan a las parejas Mallku-T'alla, aun cuando se observen diferencias. Estos no tienen el estatus de antepasados de las actuales generaciones, no son Incas, no son uywiris o awatiris, no se celebran en los cerros, pirkas o vertientes. Sus ofrendas rituales son diferentes: a los santos no se les ofrece Chuwa ni Colla. Las mesas rituales no se hacen en la piedra, ni en la tierra, sino en la mesa central de la plaza. La que se dispone en el suelo frente a la plaza se realiza en honor a Pachamama. Se dice que cada santo o virgen posee un "genio" propio: temperamento bueno o temperamento malo. Pueden ser humildes, atropelladores o poco generosos. Algunos/as son más o menos "celosos". Ello implica respeto para los ofrecimientos de sus devotos. Si no se les cumple lo prometido, castigan, trayendo enfermedades o mala suerte. Los santos son como mujer y hombre, no pueden celebrarse solos, tienen que acompañarse. Ello significa que siempre deben salir en procesión acompañados con sus compañeros de "vivienda", es decir, con quienes comparten el altar en la iglesia. Aunque los comuneros dicen que si en alguna iglesia se encuentran solos o solas, se festejan de ese modo. Sin embargo, en la mayoría de las fiestas es frecuente que se invoque a todos. Por ejemplo en Enquelga, estancia de Isluga, hay que pedir primero por "Tatita San Felipe" y por "Mamita Candelaria". Ellos viven en la iglesia como comuneros. Se les pide "Bendición" (buena cosecha, que dé alimentos); para que den suerte en el comercio; se les pide para tener buena salud; se les pide para pedir "milagros". También protegen a sus devotos como 'abogados'. Los santos principales poseen el poder de revelarse a los comuneros para la decisión de pasar el cargo de cacicazgo y las patronas a las mujeres para T'alla, el cargo más importante y el final del sistema rotativo, al que debía aspirar toda pareja adulta que quiera tener prestigio y desee morir dignamente. La celebración dura por lo general tres días y sigue la misma estructura de las demás festividades: Antevíspera, momento para llamar a los Antepasados en casa del fabriquero o casa del alférez de turno. Se trata de una ceremonia familiar: parientes cercanos a los pasantes. La víspera: Wilancha al Santísimo (Kollanta), a la Pachamama (cumplimiento) (Puerta de Iglesia, Cruz del Calvario (en cerros o lomadas), Plaza. La realizan el pasante y acompañantes (comunidad, parientes e invitados). Día Grande: Pasacalle, Procesión, Bendición a familias por todo el pueblo. Cacharpaya o día de los regalos y del Katuriri (pareja que recibe la fiesta 
para el próximo año y despedida). Baratillo en el calvario, ceremonia del Intercambio; para alcanzar lo deseado (recibiente y alférez dirigen representaciones de compra y venta). En música predominan sikura y lichiguayos, aunque las bandas de viento y bandas electrónicas complementan durante todos los días de fiesta.

Bajo otras modalidades en la precordillera se celebran también a las y los patronas/os. La fiesta de los pastores ( 6 de enero) es celebrada en varios pueblos de valles: Chiapa, Jaiña, Limaxiña, Huaviña, Sibaya, Mamiña, Parka. Esta adquiere características parecidas al wayño altiplánico; mientras que en La Tirana y Pica se asemeja más a la fiesta del 16 de julio en el mismo pueblo. En mayo la fiesta de la Santa Cruz o Cruces suele ser también celebrada en la mayoría de los valles serranos y costeros.

En las fiestas patronales la institución eclesiástica ejerce mayor autoridad. Y en aquellas en las que la participación de la población que no se adscribe étnicamente al pueblo aymara es mayor, la estructura de la festividad mencionada más arriba se desperfila. Las ofrendas de sangre, alcohol y comidas, junto con la memoria a los antepasados desaparecen, van quedando fragmentos menores. La festividad religiosa que reúne a poblaciones diversas, como La Tirana, es la más distante de las descritas aquí. No constituye un centro de peregrinación religiosa para la mayoría de los comuneros del altiplano, sino se configura como un centro comercial.

\section{Reflexiones Finales}

Las festividades religiosas celebradas en esta zona se entienden en el calendario anual, el que se percibe en un orden cósmico comandado por Inti o Dios, Pachamama, las Santas y los Santos Patronas/os.

Los datos permiten señalar que las familias aymara tarapaqueñas se han apropiado de la ideología cristiana a partir de códigos culturales locales, heredados de generación en generación, que los provee de herramientas para generar su propia comprensión religiosa. La transmisión de las prácticas y sus significados son mediadas por actores sociales concretos; en consecuencia, van experimentando variaciones de acuerdo con la experiencia de los mismos. Los contextos sociales y económicos en los que se insertan adquieren gran relevancia.
La recuperación de la memoria colectiva muestra cambios significativos en las formas de expresión religiosa. Las entrevistas indican que en un período aproximado de cincuenta años las fiestas que celebran rituales de pasajes en las localidades rurales van desapareciendo o bien son realizadas por un grupo pequeño de familias. A pesar de ello, persisten creencias que van actualizándose en formas rituales diferentes. Este es el caso de las ceremonias fúnebres en las ciudades y la recuperación de las fiestas patronales o carnavales auspiciada por el Estado chileno. Sin embargo, no sabemos cómo han sido resignificadas. Una cuestión interesante resulta saber de qué manera se transita de una concepción del tiempo circular a una lineal, concepto transmitido por el sistema escolar.

Las fiestas descritas en el tiempo-espacio circular aparecen como resistiendo los procesos de dominación cultural. Pachamama emerge como referente del pueblo "indio", categoría estigmatizante que se reconvierte al interior de la comunidad étnica en pasado positivo para sostener procesos identitarios, en medio de una colectividad que profesa universalmente una cultura cristiana, con distintas instituciones pero con una clara hegemonía de la iglesia católica. La escuela ha sido el principal mecanismo del Estado-nación de Chile para homogeneizar culturalmente a sus ciudadanos/as. Así, es posible formular la hipótesis de que la escolaridad tiene un peso mayor en los cambios que se han producido en la religiosidad durante el siglo XX, más que los procesos migratorios campo-ciudad y más que la conversión de una iglesia a otra. No obstante, la heterogeneidad cultural en Tarapacá continúa. Modernizarse con tradición parece ser compatible, puesto que los aymara proceden a reelaborar ideas y acciones de la cultura dominante, tanto como los no aymara tarapaqueños. En la actualidad no tiene el mismo significado la Virgen de La Tirana ("La Chinita") para un ex obrero del salitre o para un pescador iquiqueño que la Virgen de Copacabana para un devoto de alguna comunidad del altiplano. La fiesta de la pascua de negros no es lo mismo para los comuneros de Chiapa que para el Obispo de Iquique, quien dirige esta festividad en La Tirana. Las representaciones de Pachamama, a quien llaman también Virgina o Virgen Tayka, no son las mismas que la iglesia católica asigna a la Virgen María.

Compartimos con van Kessel la idea de que 'la cultura popular urbana' y 'la aymara andina' 
forman un continuo. No obstante, no es tan clara la continuidad de los significados entre Pachamama y la Virgen María o entre la willancha y la eucaristía. Ello porque la dimensión de la sexualidad, como base de la fecundidad, parece ser un aspecto gravitante en el rito y el mito actualmente vigentes; al menos en Isluga (cf. Martínez 2001) ${ }^{14}$. Con todo, la religiosidad contemporánea requiere mayores investigaciones empíricas en relación a los procesos de significación de las prácticas actuales, principalmente en la ciudad.

Agradecimientos: Este trabajo forma parte de los resultados de investigación del proyecto FONDECYT N ${ }^{\circ} 1050143$ y del Proyecto de
Investigación Mayor Ciencia y Tecnología, UTA, Código 3741-08, "La construcción social y simbólica de la sexualidad en mujeres y hombres indígenas y no indígenas en el norte de Chile". Agradecemos especialmente a H. González y H. Gundermann por facilitarnos las entrevistas aplicadas a comuneros de las localidades de la franja altiplánica de norte a sur de la antigua región de Tarapacá, trabajo desarrollado gracias a los proyectos FONDECYT No 191050095 y 1910034; a Michel Parra y Mónica Escobar, sociólogos, por su colaboración con las representaciones que este trabajo incluye. Igualmente agradecemos a los evaluadores, quienes se dieron el trabajo de realizar importantes sugerencias.

\section{Referencias Citadas}

Bastien, J.

1996 La Montaña y el Cóndor. Metáfora y Ritual en un Ayllu Andino. Hisbol, La Paz.

Bertonio, L.

1984 [1612] Vocabulario de la Lengua Aymara. Ediciones Ceres, Cochabamba.

Bouysse-Cassagne, T. y O. Harris

1987 Pacha: en torno al pensamiento Aymara. En Tres Reflexiones sobre el Pensamiento Andino, editado por T. Bouysse-Cassagne, O. Harris, T. Platt y V. Cereceda, pp. 11-59. Hisbol, Bolivia.

Carrasco, A.M. y V. Gavilán

2009 Representaciones del cuerpo, sexo y género entre los aymaras del norte de Chile. Chungara Revista de Antropología Chilena 41:83-100.

Cuche, D.

2004 La Noción de Cultura. Nueva Visión, Buenos Aires.

Esch-Jacob, J.

1994 Sincretismo Religioso de los Indígenas de Bolivia. Hisbol, La Paz.

García Choque, P.

2002 Breve Diccionario Aymara-Castellano, CastellanoAymara. Aru Pirwa Ediciones Instituto de Estudios Andinos Isluga, Iquique.

Gavilán, V.

2005 Identidades étnicas en Tarapacá a inicios del siglo XXI. Revista de Dialectología y Tradiciones Populares LX 2:77102.

Guerrero, B.

1990 Las Campanas del Dolor. Violencia y Conflicto en los Andes Chilenos. Ediciones el Jote Errante, Iquique. 1994 A Dios Rogando... Los Pentecostales en la Sociedad Aymara del Norte Grande de Chile. Vrije Universiteit, Ámsterdam.
Grebe, M.E.

1981 Cosmovisión Aymara. Revista de Santiago 1:61-79, Museo Nacional Vicuña Mackenna.

1996 Continuidad y cambio en las representaciones icónicas: significado simbólico sur-andino. Revista Chilena de Antropología 13:85-93.

Martínez, G.

1989 Espacio y Pensamiento. I Andes Meridionales. Hisbol, La Paz.

2001 Saxra (diablo) Pachamama, música, tejido, calendario e identidad entre los Jalq'a. Estudios Atacameños 21:133152.

van den Berg, $\mathrm{H}$.

1989 La Tierra no da así no más: los Ritos Agrícolas en la Religión de los Aymara-Cristianos de los Andes. CEDLA, Ámsterdam.

van Kessel, J.

1980 Holocausto al Progreso. Los Aymaras de Tarapacá. CEDLA, Ámsterdam.

1992a Cuando Arde el Tiempo Sagrado. Hisbol, Bolivia. 1992b La organización tempo-espacial del trabajo entre los aymaras de Tarapacá: la perspectiva mitológica. Etnicidad, Economía y Simbolismo en los Andes. II Congreso Internacional de Etnohistoria. Coroico, pp 267-298 Hisbol, La Paz.

1996 La cosmovisión aymara. En Etnografía. Sociedades Indígenas Contemporáneas y su Ideología, editado por J. Hidalgo, V. Schiappacasse, H. Niemeyer, C. Aldunate y P. Mege, pp. 169-198. Andrés Bello, Santiago.

2007 Los andino-cristianos: ¿cristianos o andinos? Volveré 27:8-16 (agosto, 2007) http://www.unap.cl/iecta/volvere. htm (consultado el 21 enero 2008). 


\section{Notas}

1 Van Kessel, quien más ha investigado sobre la religiosidad en esta región, utiliza la expresión aymara-cristianos; siguiendo la postura de van den Berg, señala: "Partimos aquí de un cristianismo inculturado desde que el andino descubrió en sus antiguas huacas e "ídolos" la calidad de icono sacramental en los que se les hace presente, activa y salvíficamente, el representado divino cristiano que en la Colonia predicaron los misioneros: Jesucristo, el Señor, La Candelaria, La Virgen, los Santos. ... El mismo andino ha sabido digerir el sermón del misionero y transformarlo en su propio ser, sin perder su identidad andina, sin abandonar su cosmovisión originaria. Supo salvar su religión como si fuera su propio 'Antiguo Testamento' y completar o enriquecerlo con el mensaje evangélico: pero el evangelio mismo, sin toda su envoltura de cultura hebraica o griega o romana o hispana, el Verbo se hizo Carne..." (van Kessel 2007:12).

2 Esch-Jacob (1994:94) asegura que según sus estudios no se podría hablar de síntesis entre las dos religiones porque la esencia del Evangelio no pertenece al pensamiento indígena como eje central.

3 El regreso del protestantismo a la recuperación de las costumbres se inscribe en un el contexto de reconocimiento de los pueblos originarios por parte del Estado y sociedad nacional.

$4 \quad$ Mallku es el término aymara para designar Señor y T'alla para Señora de gran respeto.
5 En Isluga se llamaba la fiesta del nuevo y se realizaba en el pueblo central o Marka.

6 Registro de entrevista a E.C., de la comunidad de Guallatire 1993.

$7 \quad$ Las entrevistas aplicadas en una gran parte de las localidades de la puna tarapaqueña no registran la festividad de Navidad "hacer nacimiento" que J. van Kessel describe para Lirima, comunidad altiplánica. Tampoco la registramos en Isluga durante los primeros años de la década de 1980.

$8 \quad$ Suri es el nombre aymara para avestruz.

9 Comunicación Personal de J.M de Cariquima 1998.

10 Jiwaraña en el Diccionario de Bertonio (1984 [1612]) es morir. Jiwana en lengua aymara de Isluga es 'hacer morir' (García Choque 2002).

11 Persona que puede comunicarse con las deidades y sana a la gente.

12 Relato de E.Ch en entrevista realizada por H. Gundermann en 1988

13 Testimonio de M. F. recogido en 1988.

14 A inicios del año 2005 un joven de 18 años, integrante de una familia islugueña e inmigrante de la comuna de Pozo Almonte, muere por ser devorado por Seren T'alla en el mes de diciembre. Su madre argumentó que esta vertiente es una mujer joven y hambrienta de sangre y sexo. Para un recuento de la relación sexualidad y fertilidad para todo el sector aymara chileno y andino en general, véase Carrasco y Gavilán (2009). 